\title{
Effects of Modified Atmosphere Packaging on the Longevity of Phalaeopsis Florets
}

\author{
P.J. Vergano' ${ }^{1}$ and
}

A.J. Pertuit, Jr. ${ }^{2}$

Additional index words. ornamentals, oxygen, carbon dioxide, storage

Summary. The packaging of flowering Phalaenopsis sp. orchids in sealed plastic film offers potential advantages of extending shelflife and maintaining quality by slowing respiration and protection from the hazards of retail distribution. Following treatments, 2year-old plants, each with three to nine open florets, were stored at 21 to 27C for 76 days under natural light and natural daylengths. Plants were sealed individually in bags of air, or in bags of initially $15 \% \mathrm{O}_{2}, 23 \% \mathrm{CO}_{2}$, balance $\mathrm{N}$, or $20 \% \mathrm{O}_{2}$ and $30 \% \mathrm{CO}_{2}$. Control plants were left in open air and were watered twice weekly; plants in sealed bags were not watered. Gas concentrations in the sealed bags were monitored twice weekly. The various atmospheres had no effect on floret life. Two distinct patterns of $\mathrm{O}_{2}$ and $\mathrm{CO}_{2}$ variation with time were observed, but inflorescence half-life values were not related to these patterns. Florets on plants in bags had a greater incidence of discoloration.

$P$ halaenopsis are attractive, long-lasting potted plants for which current demand exceeds supply; therefore, they have the potential for greatly expanded commercial

College of Agricultural Sciences, Clemson University, Clemson, SC 29634-0371.

Technical Contribution No. 3456 of the South Carolina Agricultural Experiment Station. Mention of a proprietary product does not imply its endorsement by us or by Clemson Univ.

'Associate Professor, Food Science Dept., Packaging Science Program.

${ }^{2}$ Associate Professor, Dept. of Horticulture. 
sales. Their environmental growth requirements (i.e., 18C, $1500 \mathrm{ft}-\mathrm{c}$ ) make them adaptable to home conditions, more so than Cattleya and Cymbidium spp. Their commercial potential has not been realized, partly because packaging for marketing through retail outlets such as supermarkets has not been developed. Also, like other orchids, they are particularly sensitive to ethylene (e.g., "dry" sepals and faster aging, etc.), a gas naturally produced by aging plants and fruit. Ethylene levels are a concern in supermarkets because flowers and potted plants often are displayed with produce. Barrier packaging such as hermetically sealed barrier plastic bags offers possibilities for extending the shelf life of Phalaenopsis: It can preclude exposure to environmental ethylene and could contain a gaseous mixture that preserves floret life. Floret life also might be extended by slowing petal respiration in a low-O, environment maintained within the barrier bag (modified atmosphere).

The objective of this experiment was to investigate the possibility of extending floret life by packaging Phalaenopsis in barrier plastic bags in atmospheres high in $\mathrm{CO}_{2}$ and low in $\mathrm{O}_{2}$ through their storage period. Previous experiments (unpublished data) on a smaller scale using a variety of modified atmospheres indicated the possibility that high $\mathrm{CO},(20 \%$ to $30 \%)$ and moderate $\mathrm{O}_{2}(2 \%$ to $20 \%)$ atmospheres have the potential to extend floret life. A secondary objective was to determine if the number of florets on an inflorescence affected floret longevity.

Although this research was not intended to be preliminary in nature, the variability encountered in the results indicated that a much more extensive study is needed. Further studies should better control plant size and stage of development. The results reported describe the best discernible patterns revealed after 4 years of research on modified-atmosphere packaging of cut flowers and flowering plants.

Past research. Controlled atmosphere (CA) storage of fruits and vegetables, in which the atmosphere is monitored continually and held within narrow limits, is a well-developed commercial technology (Metlitsltii et al., 1983). Modified atmosphere (MA) packaging, in which an initial atmosphere other than air or vacuum is established in a package, is also a welldeveloped commercial technology for food packaging (Blankenship, 1985; Calderon and Barkai-Golan, 1990; ICCA, 1984; Ooraikul and Stiles, 1990; Robertson, 1993). For example, MA packaging is used commercially to extend the shelf life of broccoli and cauliflower florets (Packaging Digest, 1988).

For flowers, however, MA and CA storage has not been used extensively. Halevy and Mayak (1989) noted that this is due to difficulties in controlling optimum levels of $\mathrm{O}_{2}$ and $\mathrm{CO}_{2}$. Eisenberg (1985) presented eight reasons for the lack of interest in CA or MA storage of ornamentals. These include alternative solutions available for storage problems and the large number of cultivars involved, with little probability that a universal atmosphere can be found. An extensive review of the research on $\mathrm{CA}$ and $\mathrm{MA}$ storage of cut flowers supports this latter observation (Goszcynska and Rudnicki, 1988).

Only a few reports have appeared on MA packaging of potted plants. Harbaugh et al. (1976, 1978) evaluated the use of sealed polyethylene/ polypropylene bags, but they did not carry out atmospheric analyses. As an example, their results for three cultivars of Chrysanthemum morifolium were remarkably different-one cultivar was $100 \%$ "marketable" after 30 days, while the other two were $0 \%$ "marketable." An earlier successful study with chrysanthemums sealed in polyethylene bags for 17 days was reported (Harrison et al., 1972). A patent for a sealed package for potted plants was granted in 1978 (Shore, 1978). In the only reported study of MA storage of orchids (Akamine, 1981), cut florets were stored for 2- or 3-day periods. Optimum levels of $1.5 \%$ to $2.0 \%$ $\mathrm{CO}_{2}$ and $\approx 5 \% \quad \mathrm{O}_{2}$ were found, based on resistance to fading of Tranda 'Miss Joaquim'.

\section{Methods and procedures}

Phalaenopsis plants. T w oyear-old, white Phalaenopsis seedlings from the same cross were obtained from Carter and Holmes Orchids, Newberry, S.C. Each plant was in a $900-\mathrm{cm}^{3}$ pot and had initiated three to nine florets-some fully opened at treatment application. Plant heights ranged from 25 to $66 \mathrm{~cm}$. All the open florets were $\approx 8 \mathrm{~cm}$ wide.
Preparation of plants. Initially, all the plants were watered thoroughly. Each plant and its flowering stem then was sprayed lightly with Domain, FL (a.i. 46,2\%) (Grace-Sierra) at $2.98 \mathrm{ml}$. liter $^{-1}$ for Botrytis control. The following day, the 40 plants were divided at random into four groups of 10 plants each per treatment and arranged in a completely randomized design until final data were recorded. The number of florets on an inflorescence was ignored in randomly dividing the plants.

Barrier bags. The 6-pm-thick polymer film bags used were clear multilayered bags fabricated of Cryovac 5401, a film normally used for packaging meat or poultry. The bags measured $38 \times 66 \mathrm{~cm}$. Permeability values were measured for this experiment using a Macon Oxtran for $\mathrm{O}_{2}$ and a Macon Permatron-W600 for moisture. Standard ASTM Methods D3985 and F-1249 were used, respectively, for $\mathrm{O}_{2}$ and for water vapor. The volume of each bag was $\approx 23$ liters after sealing.

Gas mixtures. Gas mixtures were prepared using tanks of compressed $\mathrm{O}_{2}, \mathrm{CO}_{2}$, and $\mathrm{N}_{2}$, each regulated to a pressure of $0.21 \mathrm{MPa}$. Individual flowregulating valves were attached to the gas lines. The gas lines were connected to a manifold, in which the gases mixed. A single tube from the manifold brought the mixed gas into individual bags. The valves were adjusted to produce predetermined gas mixtures. Valve settings were determined by a trial-and-error process of filling a bag, sealing it, then analyzing its gas content. When the target gas mixture was produced initially empty sealed bags, the valves settings were unchanged. Bags filled with plants then were purged individually and sealed with the target gas mixture.

Modified atmosphere sealing. Control plants were not bagged, but simply subjected to ambient conditions. The second treatment consisted of plants sealed individually in bags of air; the third of plants sealed in a gaseous mixture of $\approx 15 \% \quad \mathrm{O}_{2}, 23 \% \quad \mathrm{CO}_{2}$, and balance $\mathrm{N}_{2}$, and the fourth of plants sealed in a gaseous mixture of $20 \% \mathrm{O}_{2}, 30 \% \mathrm{CO}_{2}$, and $50 \% \mathrm{~N}$, . To maintain high $\mathrm{RH}$, an $8-\mathrm{cm}^{3}$ sponge containing $\approx 7 \mathrm{ml}$ of water was placed in each bag. A septum on each bag allowed for gas sampling, as required. Sealing was accomplished with a 150C resistance bar applied for $1 \mathrm{sec}$. 
Sample storage. Plants were placed in a 21-27C laboratory for subsequent observations. They received natural (at plant level) light and natural daylengths (from 21 May to 15 Aug.: $14 \mathrm{~h}, 9 \mathrm{~min}$, increasing to $14 \mathrm{~h}$, $32 \mathrm{~min}$, then decreasing to $13 \mathrm{~h}, 30$ min). The natural light was from windows with exposures around three sides of the storage room (north, east, and south). Atmospheres were monitored for 64 days, but the experiment lasted for 76 days, until all the florets had wilted.

Atmosphere determinations. One-milliliter gas samples were drawn twice weekly from each bag via a syringe inserted through a septum. The first samples were taken 1 day after the bags were sealed, and subsequent samples were taken every Tuesday and Friday, following an initial Friday sampling.

Gas samples were analyzed for $\mathrm{O}_{2}, \mathrm{CO}_{2}$, and $\mathrm{N}_{2}$ using a FischerHamilton Model 29 gas partitioner. This gas chromatograph is equipped with two columns in series: a $30 \%$ DEGS on $60 / 80$ Chromosorb PNAW $(6 \mathrm{ft} \times 0.25 \mathrm{inch})$ and a $80 / 100 \mathrm{mo}-$ lecular sieve $5 \mathrm{~A}(6 \mathrm{ft} \times 3 / 16 \mathrm{inch})$ run at $20 \mathrm{C}$ with a continuous helium flow of $32 \mathrm{~cm}^{3} \cdot \mathrm{min}^{-1}$. Each analysis required $\approx 12 \mathrm{~min}$.

Evaluation of inflorescence life. Each inflorescence was examined six times per week. In previous trials, attempts were made to record the stages of quality degradation of the florets. Because each floret had been found to exhibit an individual progression of changes, in this study florets were recorded as either wilted or not wilted. A floret was rated as "dead" when its petals began to wilt, usually 2 to 3 days after its pedical changed from green to white while forming an abscissionlayer.

At each examination, the number of nonwilted florets was recorded. To allow for differing initial numbers of florets, the life of each plant's inflorescence was defined as the length of time following treatment application until one-half of its florets wilted. For plants with an odd number of florets, inflorescence life was based on the date midway between the date when more than half and that when just less than half the number of florets wilted.

\section{Results}

Permeability determination. The measured value for oxygen per-
Table 1. The effect of four treatments on storage life of potted Phalaenopsis sp.

\begin{tabular}{llccc}
\hline & & \multicolumn{2}{c}{ Inflorescence life (days) } & \\
\cline { 3 - 4 } Treatment & Atmosphere & Mean & Range & $\sigma_{n=1}$ (sD) \\
\hline 1 & Control (open air) & 38 & $16-61.5$ & 17 \\
2 & Air (sealed in bag) & 40 & $22.5-51$ & 10 \\
3 & $15 \% \mathrm{O}_{2}, 23 \% \mathrm{CO}_{2}$ & 43 & $31-60$ & 9 \\
4 & $20 \% \mathrm{O}_{2}, 30 \% \mathrm{CO}_{2}$ & 43 & $7-60$ & 15 \\
\hline
\end{tabular}

meation coefficient through the barrier film was $0.8 \mathrm{~cm}^{3} \mathrm{O}_{2} / \mathrm{mm}$ per $\mathrm{m}^{2}$ per atmosphere per day with a $100 \%$ $\mathrm{O}_{2}$ gradient. For water vapor permeanon, the measured permeation coefficient was $0.05 \mathrm{~g} / \mathrm{mm}$ per $\mathrm{m}^{2}$ per day with a relative humidity difference of $100 \%$. Both measurements were made at $23 \mathrm{C}$.

Half-life of inflorescence. The mean half-life values of the four treatments (Table 1) were not significantly different $(\mathrm{a}=0.05)$. The longevity of the inflorescences was the same whether they are left in open air and watered every 3 or 4 days, sealed in air, or stored in elevated CO, atmospheres.

Changes in gas concentrations during storage. The initial $\mathrm{CO}_{2} \mathrm{con}$ centration for plants initially sealed in air averaged $\approx 6 \%$; much higher than expected (Fig. 1). The $\mathrm{O}_{2}$ and $\mathrm{CO}_{2}$ average values for these plants remained in a narrow range over the course of the experiment. The $\mathrm{CO}_{2}$ concentra- tion gradually decreased to $-3.5 \%$. The $\mathrm{O}_{2}$ concentration decreased to $\approx 13 \%$ between days 15 and 19 , then slowly increased to $\approx 16 \%$.

All of the plants initially sealed in air, and four of the 10 plants initially sealed in $15 \% \quad \mathrm{O}_{2}$ and $23 \% \mathrm{CO}_{2}$, exhibited atmospheric change patterns similar to that in Fig. 1. The pattern consisted of two curves that did not intersect. The $\mathrm{O}_{2}$ concentration remained above the $\mathrm{CO}_{2}$ concentration for the duration of the experiment. Five of the 10 plants initially sealed in $20 \% \mathrm{O}_{2}$ and $30 \% \mathrm{CO}_{2}$ also exhibited this pattern.

For plants originally in $15 \% \mathrm{O}_{2}$ and $23 \% \mathrm{CO}_{2}$, the initially measured $\mathrm{C} \mathrm{O}_{2}$ concentration, at $\approx 11.5 \%$, was lower than expected (Fig. 2). The $\mathrm{CO}_{2}$ concentration, on average, increased above the $\mathrm{O}_{2}$ concentration after day 15. The $\mathrm{O}_{2}$ concentration decreased at the same time. The average $\mathrm{CO}_{2} \mathrm{con}$ centration remained above the $\mathrm{O}_{2}$ level until after day 43. The $\mathrm{O}_{2}$, concentra-

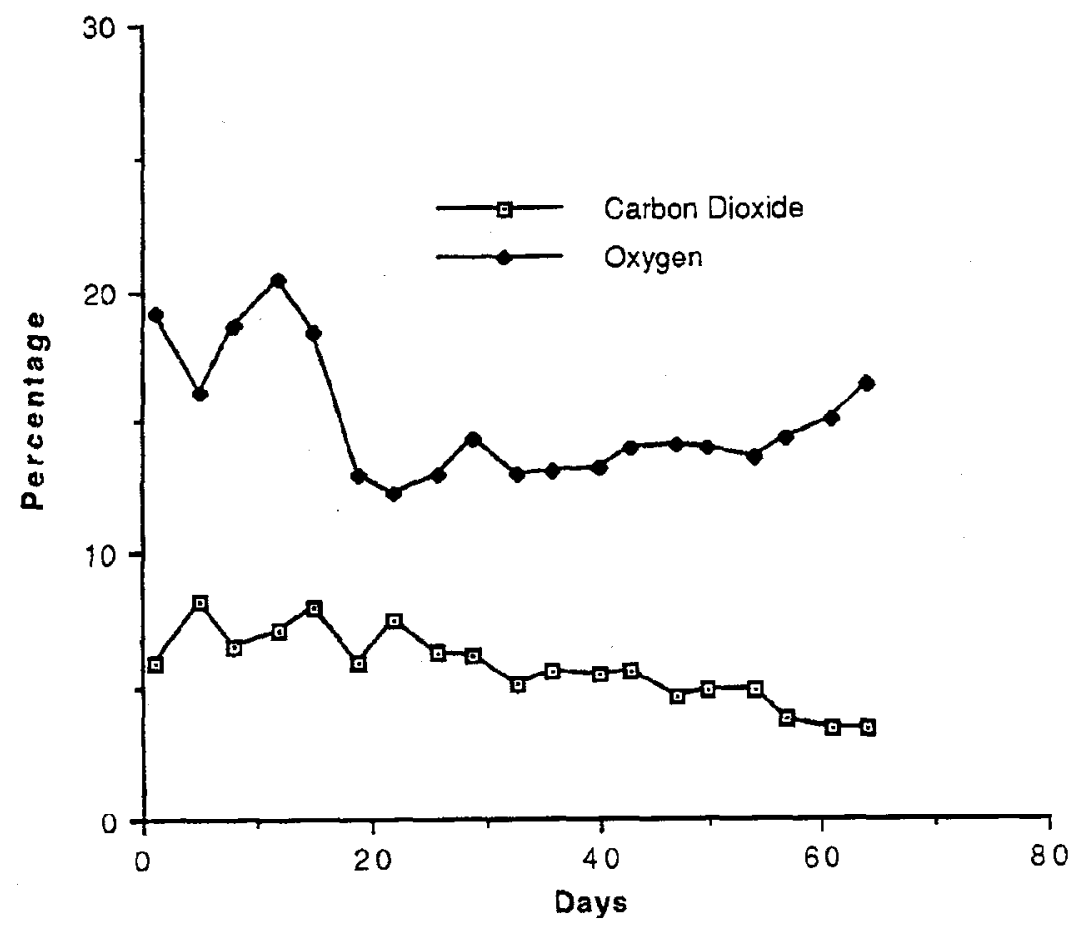

Fig. I. Oxygen and $\mathrm{CO}_{2}$ concentrations around potted Phalaenopsis sp. sealed initially in air (mean values for nine plants). 


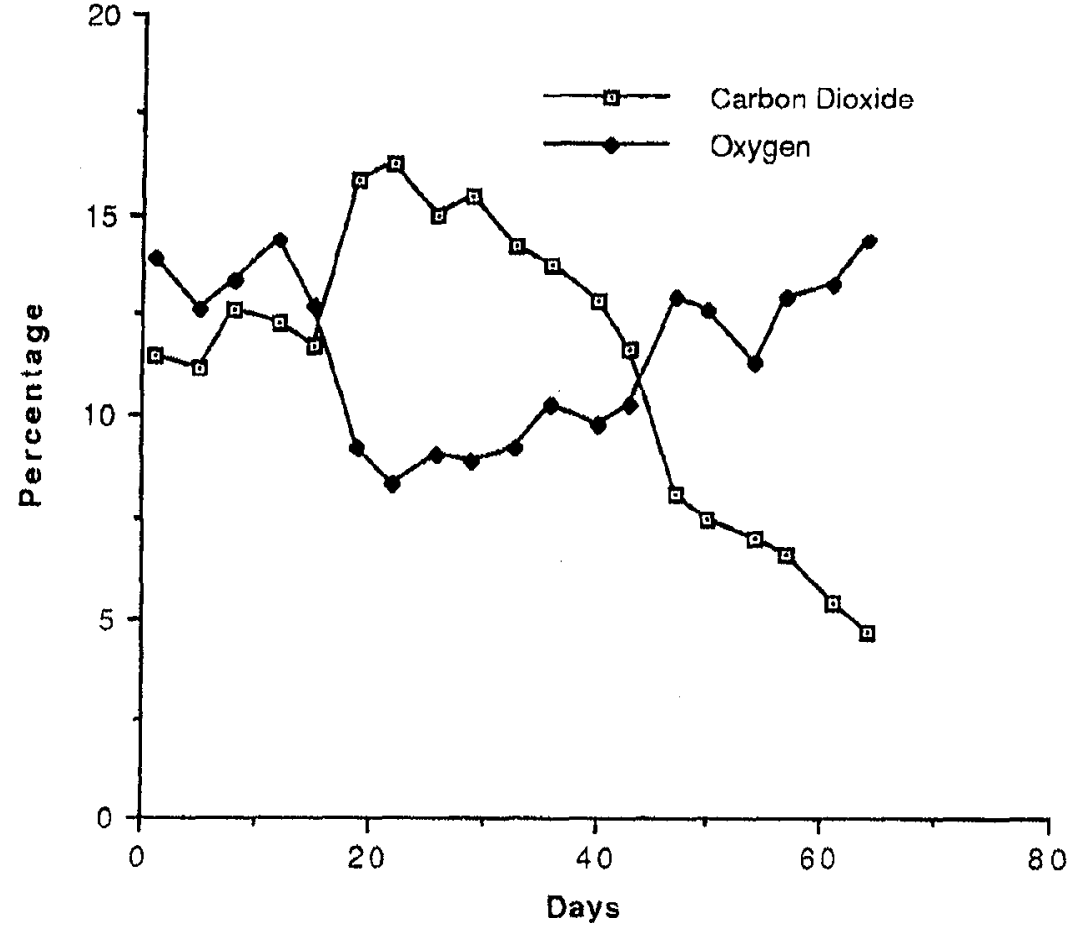

Fig. 2. Oxygen and $\mathrm{CO}_{2}$ concentrations around potted Phalaenopsis sp. sealed initially in $15 \%$ $\mathrm{O}_{2}, 22.5 \% \mathrm{CO}_{2}$, and $62.5 \% \mathrm{~N}_{2}$ (mean values for 10 plants).

tion continued to increase after day 43 , while the $\mathrm{CO}_{2}$ concentration continued to decrease. Six of 10 plants initially sealed in $15 \% \quad \mathrm{O}_{2}$ and $23 \% \mathrm{CO}_{2}$ exhibited atmospheric patterns in which $\mathrm{CO}_{2}$ levels greatly exceeded $\mathrm{O}_{2}$ levels for 20 to 30 days during the 64 days of atmospheric monitoring (Fig. 3). The pattern for mean atmospheric

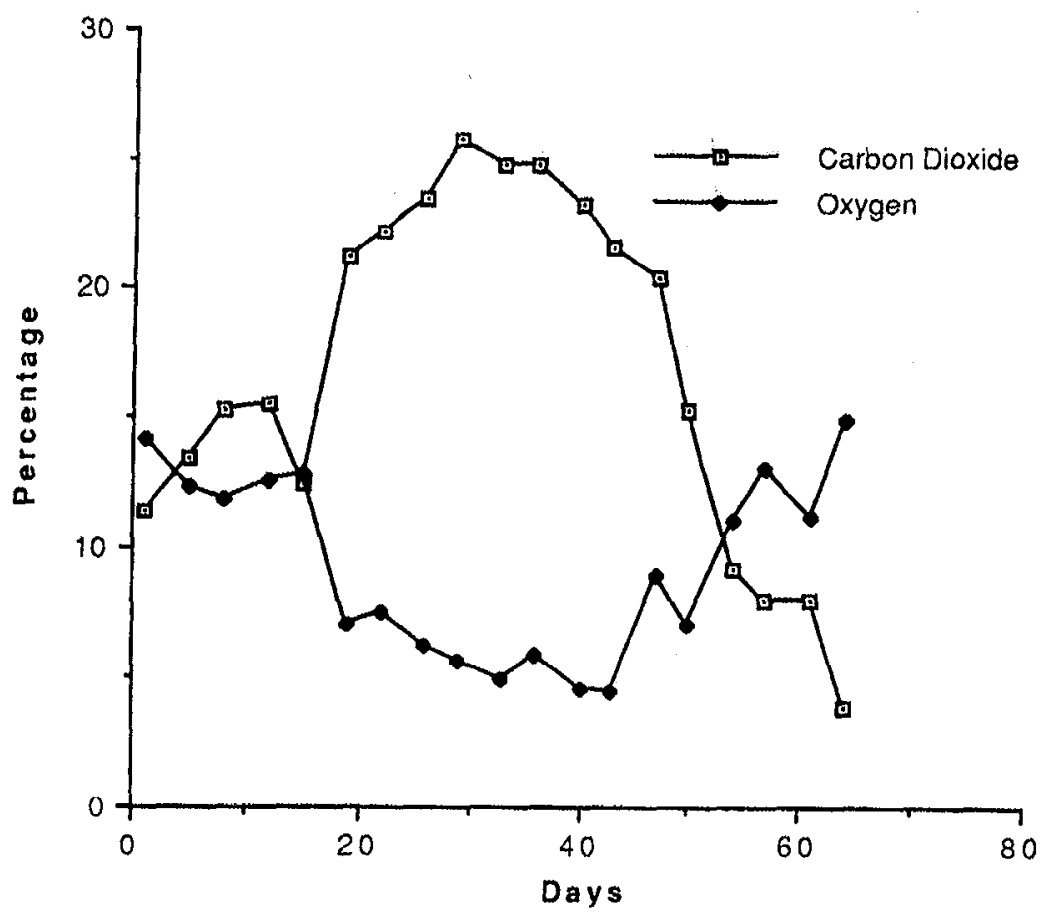

Fig. 3. Example of $\mathrm{O}_{2}$ and $\mathrm{CO}_{2}$ concentrations around one potted Phalaenopsis sp. sealed initially in $15 \% \mathrm{O}, 22.5 \% \mathrm{CO}_{n}$ and $62.5 \% \mathrm{~N}_{n}$.
Fig. 2. The initial measured concentrations for $\mathrm{O}_{2}$ and $\mathrm{CO}$, respectively, for these plants were $\approx 18 \%$ and $13 \%$. The initial $\mathrm{CO}_{2}$ concentration was much lower than expected. The data presented in Fig. 4 resulted from five plants that exhibited a pattern seen in Fig. 1 and five plants with a pattern seen in Fig. 2 or 3.

The mean life of inflorescences of plants exhibiting atmosphere-time patterns exemplified by Fig. 1 was 43.1 days $(\sigma=9.6$ days); for those of the pattern seen in Fig. 3, it was 39.8 days $(\sigma:=14.9$ days). Applying a $t$ test analysis, the mean lives of inflorescences for the two types ofatmosphere patterns are indistinguishable at $95 \%$ and even at $80 \%$ levels of significance.

Number of florets effect on longevity. Data in Table 2 compare inflorescence life to the total number of florets on the plant. Of the 40 plants studied, only three had five original florets, and the standard deviation for their inflorescence life is understandably large.

A $t$ test analysis indicates that the means for inflorescence life are not distinguishable at an $80 \%$ level of confidence. A correlation analysis of these data indicates that there is no significant linear relationship between inflorescence life and number of florets (Pearson correlation coefficient, $r=$ 0.14). Both results indicate that the random grouping of plants that ignored the number of florets on each plant was appropriate in this research.

Appearance of plants and florets sealed in barrier bags. No difference was apparent in the appearance of the leaves of the plants sealed in modified atmospheres for the 76-day duration of this study. No plants wilted.

Some of the florets sealed in barrier bags, however, exhibited petal discoloration when their petals made contact with moisture condensed on the inside of the bags. None of the florets on the control plants had observable discoloration.

\section{Discussion}

Results reveal that none of the modified atmospheres studied increased inflorescence life over that of Phalaenopsis simply placed in air. The fact that $\mathrm{CO}_{2}$ levels increased to $\approx 30 \%$ while $\mathrm{O}_{2}$ levels decreased to $\approx 5 \%$ (as seen in Fig. 3) without affecting floret longevity suggests that floret longevity is not strongly dependent on stor- 


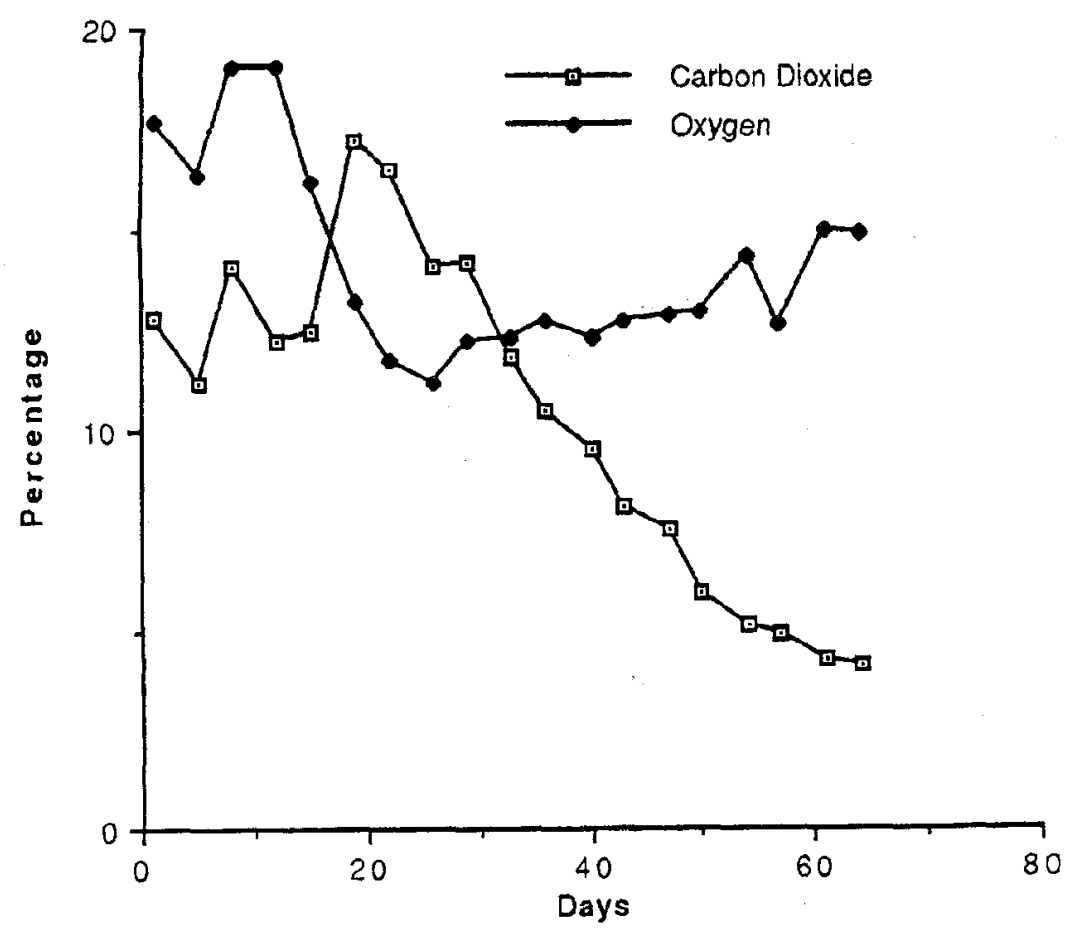

Fig. 4. Oxygen and $\mathrm{CO}_{2}$ concentrations around potted Phalaenopsis sp. sealed initially in $20 \%$ $\mathrm{O}_{2}, 30 \% \mathrm{CO}_{2}$, and $50 \% \mathrm{~N}_{2}$ (mean values for 10 plants).

age atmosphere over these values. The use of air as the initial atmosphere, of course, simplifies and lowers the cost of packaging in a sealed environment.

The gas concentrations in the barrier bags did not change abruptly when florets wilted. The respiration and photosynthesis of the leaves of the plants appear to have dominated any effects caused by changes in the florets. As pointed out by Eisenberg (1985), one of the reasons "CA storage work in ornamentals is lacking" is the fact that they include leaves, roots, and flowers, "and each reacts differently to CA." The atmospheres measured in this study were summations of reactions occurring in different plant parts.

The advantages of storing in barrier bags are: The plants can survive without being watered and they are not subjected to potentially harmful environments (e.g., ethylene). Harbaugh et al. (1978) observed the

Table 2. The effect of number of florets on inflorescence life of potted Phalaenopsis sp.

\begin{tabular}{lllc}
\hline \multirow{2}{*}{$\begin{array}{l}\text { No. } \\
\text { florets }\end{array}$} & \multicolumn{2}{l}{ Inflorescence life (days) } \\
\cline { 2 - 4 } & Mean & Range & $\sigma_{\text {n-1 }}(\mathrm{SD})$ \\
\hline 3 & 38.3 & $22.5-45$ & 12.8 \\
4 & 37.3 & $21-51$ & 10.5 \\
5 & 30.3 & $16-53.5$ & 20.2 \\
6 & 48.6 & $32-60$ & 10.2 \\
7 & 45.7 & $38-55.5$ & 6.3 \\
\hline
\end{tabular}

former. This is significant if plants such as Phalaenopsis are to be distributedvia efficient distribution systems now used for mass retail marketing.

The presence of condensate in the bags and floret discoloration associated with it suggests that the polymer bags or other packaging chosen to package flowers for mass market retail distribution should be selected for their water vapor permeation properties. Ideally, bags should be sufficiently moisture-permeable to prevent excessive moisture buildup or condensate.

To avoid petal discoloration, a rigid package and a means of supporting the peduncle to keep the florets from contacting the package are both desirable.

\section{Literature Cited}

Akamine, E.K. and T. Goo, 1981. Effects of static-controlled atmosphere and reduced pressure on fading of Vanda Miss Joaquim flowers. Hawaii Inst. of Tropical Agr. and Human Resources, College of Tropical Agriculture and Human Resources, Univ. of Hawaii at Manoa, Honolulu. Res. Ser. 008 .

Packaging Digest. 1988. FRESHHOLD buys time for produce. Packaging Dig. Nov. p. 124, 128, 130, 144.

Blankenship, S.M. (ed.). 1985. Controlled atmospheres for storage and transport of perishable agricultural commodities. Proc.
Fourth Natl. Controlled Atmosphere Res, Conf. 23-26 July 1985. Dept. of Horticultural Science, North Carolina State Univ. Raleigh. Hort. Rpt. 126.

Calderon, M. and R. Barkai-Golan (eds.). 1990. Food preservation by modified atmospheres, CRC Press, Boca Raton Fla.

Eisenberg, B.A. 1985. A summary of CA requirements, limitations, and recommendations for ornamentals. Controlled atmospheres for storage and transport of perishable agricultural commodities. Proc. Fourth Natl. Controlled Atmosphere Res. Conf. 23-26 July 1985. Dept. of Horticultural Science, North Carolina State Univ. Raleigh. Hort. Rpt. 126.

Goszynska, D.M. and R.M. Rudnicki, 1988. Storage of cut flowers. Hort. Rev. 10:35-62.

Halevy, A.H. and S. Mayak 1981. Senescence and postharvest physiology of cut flowers II. Hort. Rev. 3:59-143.

Harbaugh, B.K., G.J. Wilfret, A.W. Englehard, and W.E. Waters. 1976. Evaluation of 40 ornamental plants for a mass marketing system utilizing sealed polyethylene packages. Proc. Fla. State Hort. Soc. 89:320-323.

Harbaugh, B.K., G.J. Wilfret, and F.J. Marousky. 1978. Use of sealed polyethylene packages for marketing potted plants. HortScience 13(6):669-670.

Harrison, M.R., D. Durkin, and F. Hanlon. 1972. The effect of pressurized sealed film packaging on the keeping quality and shelf life of three chrysanthemum cultivars, Pennsylvania Flower Growers Bul. 258.

ICCA. 1984. CAP '84: Proc. Intl. Conf. on Controlled Atmosphere Packaging, 29 Oct. 1984, Ritz-Carlton Hotel, Chicago. Intl. Conference on Controlled Atmosphere Packaging. Schotland Business Research, Princeton, N. J.

Metlitskii, L.V., E.G. Sal'-Kova, N.L. Volkind, V.I. Bondarev, and V.Y. Yanyuk. 1983. Controlled atmospheric storage of fruits. U.S. Dept. of Agriculture and the National Science Foundation, Washington, D.C., [published by Amerind Publ. Co.; New Delhi. Available from the U.S. Dept. of Commerce, National Technical Info. Serv. (Original publisher: E 'Konomika Publishers, Moscow, 1972).

Ooraikul, B. and M.E. Stiles. (eds.). 1990. Modified atmosphere packaging of food. Ellis Horwood ser. in food science and technology. E. Horwood, New York.

Robertson, G.L. 1993. Packaging of horticultural products. Food packaging, principles and Practice, Marcel Dekker, New York, 1993. p. 470-506.

Shore, W.S. 1978. Plant package. U.S. Patent No. 4, $118,890$. 